\title{
Investigating the Relationship between Emotional Intelligence and Job Performance among Academic Administrative Management Group at Mara University of Technology (UiTM) Southern Zone Campuses, Malaysia
}

\author{
Wan Aisyah Amni binti Wan Mohamad Saferdin', Gladys Sebi binti Entigar ${ }^{2}$, \\ Nurbarirah binti Ahmad ${ }^{3}$, Siti Rosnita binti Sakarji ${ }^{4}$, Khalijah binti Mohd Nor ${ }^{5}$ \\ ${ }^{1}$ UiTM Kampus Alor Gajah, Melaka, Malaysia, $\square$ (e-mail) aisyah606@melaka.uitm.edu.my \\ 2 UiTM Kampus Samarahan, Sarawak, Malaysia $\bowtie$ (e-mail) gladys@sarawak.uitm.edu.my \\ ${ }^{3}$ UiTM Kampus Alor Gajah, Melaka, Malaysia, $\square$ (e-mail) nurbarirah497@melaka.uitm.edu.my \\ ${ }^{4}$ UiTM Kampus Alor Gajah, Melaka, Malaysia, $\bowtie$ (e-mail) rosnita507@melaka.uitm.edu.my \\ ${ }^{5}$ UiTM Kampus Alor Gajah, Melaka, Malaysia, $\bowtie$ (e-mail) khalijah904@melaka.uitm.edu.my
}

\begin{abstract}
Emotional intelligence (EQ) has become increasingly popular as potential underlying attribute of effective leadership and organizational performance. Emotional intelligence is described as a set of abilities that refer in part to how effectively one deals with emotions both within oneself and others. This study was conducted to investigate the relationship between emotional intelligence and job performance among academic administrative management group at Mara University of Technology (UiTM) Southern Zone Campuses, Malaysia which consisting of three state branches; Melaka, Johor and Negeri Sembilan. The questionnaires were personally administrated to the targeted respondents that comprised of Deputy Directors, Heads of Program and Program Coordinators. The outcomes of testing research hypotheses using a statistical analysis showed that emotional intelligence significantly correlate with job performance. The results of this study could be used to create the awareness on the importance of emotional intelligence in developing human capital among academic staff in UiTM. Thus, when specific skills have been identified as a crucial to job performance, programs could be designed in developing these skills to facilitate better performance for academic administrator in UiTM.
\end{abstract}

Keywords: emotional intelligence, job performance, and academic administrative management group

\section{Introduction}

The impact of leadership on organizational change and performance has been the subject of extensive research and a number of research studies have focused on the connection between leadership and organizational success (Kotter, 1990). One variable that has recently gained much popularity as a potential underlying attribute towards the work performance was the construct of emotional intelligence (Rohana Ngah, Kamaruzaman Jusof and Zanariah Abdul Rahman, 2009). Emotion is a critical in motivating, persuading, communicating, leading and controlling individuals and groups. (Rohana Ngah et al., 2009). Emotional intelligence is describes as a set of abilities that refer in part to how effectively one deals with emotions both within oneself and others (Salovey and Mayer, 1990). It has been proposed that in leadership, dealing effectively with emotions may contribute to how one handles the needs of individuals, how one effectively motivates employees, and makes them "feel" at work (Goleman, 1998b).

While emotional intelligence is a new era of investigation for job performance and organizational success, it was proved to be an area of significant importance. People with high emotional intelligence are more likely than less emotionally intelligence people to 'gain success' in the workplace because it can improve performance both employees personal levels and organizational levels (Goleman, 1998a). He pointed out that managers with high emotional intelligence are likely to 
provide their organization with a unique contribution but has not yet received much empirical attention and support particularly with regard to various important work-related attitudes and behavior outcomes that serve as good indexes for investigation. Nevertheless, the awareness on the importance of emotional intelligence in enhancing job performance in the public higher learning institution was still low as the focus is more on "working skills" rather than "people skills".

The public higher learning institution's environment especially in universities today is very challenging and demanding due to the changes of policies and the increasing standard and expectation of education in Malaysia (Rohana Ngah et al., 2009). This has created urgent demands on the role of the university staff as they are moving towards a world class university by restructuring the institutions in the context of research, curriculum, teaching and learning, industrial linkages, infrastructure, networking and training. The staff especially academic staff not only needs to focus on teaching but also to embark on professionalism, managerial and leadership capabilities.

Therefore, a new set of knowledge, skills and abilities, perhaps a whole new configuration of personality and intelligent requirements needs to be considered in the work of human resource management. These may include flexibility, adaptability, self-management, motivation, intuition, empathy, cooperation, collaborative problem-solving, conflict management, interpersonal sensitivity, commitment and cultural awareness. These competencies are components of another important aspect of human resource management, that is, emotional intelligence that can predict job performance (Meyer and Allen, 1997; Fineman, 1997).

The management of Mara University of Technology's (UiTM) has put the interest on the development of human capital among academic and non academic staff in their preparation to accomplish the mission to become a world class university. UiTM's Vice Chancelors, Prof Emeritus Dato' Dr. Hassan Said had urged the academic and non academic administrators to enhance their management quality and other human capital aspects while launching the 2016 Quality Week at Mara University of Technology, Shah Alam Campus, Selangor. This was based on complaints that some administrators among the academic staff and non academic staff have difficulty working within a team, communicating orally especially in managing their subordinates, lack of co-operation with their subordinate, tactless in their interactions with other

Furthermore, exactly how, and to what extent emotional intelligence influence job performance is currently unknown. In addition, the relationship between emotional intelligence and job performance in Malaysia's public university is not highly researched. At present, the theoretical linkages between emotional intelligence and job performance in the higher learning institution are not fully established by past researchers. Therefore, it is the aim of this study to explore and test a framework to explain the relationship between emotional intelligence and job performance. So, the question is to what extent does the influence of emotional intelligence on job performance among academic administrators in UiTM.

The study of emotions has played a major role in organization studies. Researcher has described the benefits of possessing a high emotional intelligence. This study will enrich and add to the literature on emotional intelligence in the work place. The findings will also provide an understanding and the importance of emotional intelligence among employees in an organization especially in the university. Thus, it can assist UiTM in determining the type of leadership style and motivational strategies needed by their employees. Once an accurate assessment of the emotional intelligence level as well as their relationship with job performance has been identified, then UiTM can educate and create the awareness on the importance of emotional intelligence in developing human capital among them.

Furthermore, knowledge regarding exactly how emotional intelligence relates to job performance may lead to significant advances in leadership training and development programs, and the ability to select potentially effective leaders. So, the completion of the research should therefore enable the researcher to identify the emotional intelligence skills that need to be developed through training 
needs analysis to indicate skills that are the most significantly related to job performance. Thus, when specific skills are identified as being critical to the determination of success, then, programs can be designed to help develop these skills to facilitate better performance for academic administrators in UiTM.

These findings may be viewed with a few limitations in mind. This project is a first attempt to compare the emotional intelligence of the individuals in the higher learning institution with their job performance. The researchers only use one sample of university at Malaysia which is Mara University of Technology (UiTM) Southern Zones Campuses which consisting of three state branches: Melaka, Johor and Negeri Sembilan. Data collected from the present study were drawn solely from a random sample of 59 academic administrators working in UiTM Southern Zone Campuses and thus, represent one university of the country. Therefore, generalization should be confined to those academic administrators working in UiTM Southern Zone Campuses only. The findings will be limited by using only three sources of population from UiTM Melaka, Johor and Negeri Sembilan. The choice of conducting this research on these three areas is because of the availability of resources such as time consuming and costs that may incurred.

In addition, when self-assessment instruments are given to academic staff, they usually evaluate themselves as supportive, caring people. However when these same people are evaluated on the same instrument by the people who work for them, they are not seen as supportive, caring people. The reality is that unless we express our good feelings, people often do not know they exist. People are not mind readers (Edwards and Ewen, 1996). Self-ratings have been shown to be inflated due to a self-serving bias, that is, some individuals tend to have a higher opinion of them than do others. If there is a lack of knowledge or insight, individuals will tend to raise their self-assessment. In the case of minority groups, the reverse is true, that is, they tend to assess themselves lower than do majority groups (Edwards and Ewen, 1996).

\section{Methods}

Coolican (1999) stated that a research design provided an overall structure and strategy of the research as it gave information of how research data were collected, analyzed and interpreted. This study is a quantitative research study. Creswell (1994) defined q on theory composed of variables, measured with number and analyzed with statistical procedures, in order to determine whether the predictive generalizations of the theory hold true.

This study is designed to use a descriptive correlational design to examine the relationships between job performance, the dependent variable and the selected independent variables and their dimension. Firstly, the dependent and the independent variables were identified. Then, the measurement scales of the identified variables were sought and determined. Before using the measurement scales, the validity and reliability of the scales is assessed. Secondly, a representative sample was selected to represent the population of the study so that the results of the study can be generalized to the population at large. A good decision model based on Krejcie and Morgan (1970) was used to determine an appropriate sample size.

Next, the data were collected from the sample using the validated and reliable research instrument. After the data were collected, they were analyzed using a combination of statistical analyses such as descriptive statistic, correlation and multiple regression analysis. Among the descriptive statistics were frequency distribution, measures of central tendency and measures of variability. Correlation analysis was used to determine the relationship between the relationship between the independent and dependent variables. This study also incorporated multiple regression analysis to ascertain the contribution of each of the significant predictor variables towards the variance in the dependent variable.

The sampling frame used was drawn from the directory of academic administrative management group in UiTM Southern Zone Campuses of Malaysia that consists from three UiTM state branches; 
Melaka, Johor and Negeri Sembilan. The lists of name, position, program, address and phone numbers was taken from the directory.

The population of the study was the academic administrative management group from three UiTM state branches; Melaka, Johor and Negeri Sembilan. The academic administrators comprise of Deputy Directors, Head of Program and Program Coordinators. Therefore, the total population from three UiTM branches consists of 70 academic administrators whereby $\mathrm{N}=70$. Table 3.1 below shows the population of the study from three UiTM state branches.

Questionnaires were used as a research instrument to collect data from the respondents identified for this study. The questionnaire consisted of 6 pages containing four three sections. Section A consisted of a Respondent's Profile; section B consisted of a list of items to measure emotional intelligence; and section C comprised items to measure job performance. The Respondent's Profile section was intended to provide background information as to the type of respondents under study with respect to personal characteristics. Respondents were asked to provide demographic information and profession information. Information pertaining to their demographic includes gender and age. Meanwhile information pertaining to their profession includes education attainment, job status and working experience.

The Emotional Intelligence section was intended to indicate the level of emotional intelligence among academic staff in UiTM. The section consisted of 3 specific dimensions of emotional intelligence namely self-management, relationship-management and communication. Each component consisted of 6 statements and total up to 18 statements for this section. The Emotional intelligence section referred to the capacity for recognizing an academic staff's feelings and those of others, motivating one-self, and for managing emotions well personal and social development of one's being. In this study, the People Index was used as the indicator of emotional intelligence was conceptually based on the Goleman organizational model of emotional intelligence focusing on three specific areas includes self-management, relationship-management and communication. Using selfreport-paper-pen, straight answer questionnaire techniques, academic staff were asked to rate their preference on a 5-point Likert scale on which they were to indicate whether items were "strongly agree", "agree", "neutral or uncertain", "disagree" or "strongly disagree" characteristic of themselves.

The Job Performance section was intended to indicate the level of job performance among academic staff in UiTM. The section consisted of 4 components of job performance namely Communication skill, Problem solving skill, Task-management skill and Interpersonal skill. Each component consisted of 5 statements and total up to 20 statements for this section. The concept of job performance was assessed using items developed by Nowack in 1997 as the job performance scale.

In this study, job performance, the dependent variable was defined in terms of outcomes, or behavior of an academic staff's communication, problem-solving, task-management and interpersonal performance that in turn lead to desired outcomes. Using self-report-paper-pen, straight answer questionnaire techniques, academic staff were asked to rate their preference on a 5point Likert scale on which they were to indicate whether items were "strongly agree", "agree", "neutral or uncertain", "disagree" or "strongly disagree" characteristic of themselves.

\section{Data Analysis}

This study used stepwise regression method to determine those independent variables that contributed most significantly to the prediction of the criterion variable. Before the next independent variable was included, the variable must significantly improve the regression model or it would be dropped from the model. According to Berenson and Levine (1996), variables in stepwise regressions could be "added to" or "deleted from" the regression model at each step. The stepwise procedure would come to a halt when these variables did not satisfy the entry statistical criterion. Thus, the end result of the analysis was a best fitting regression model. The equation for the multiple linear regression model was: 


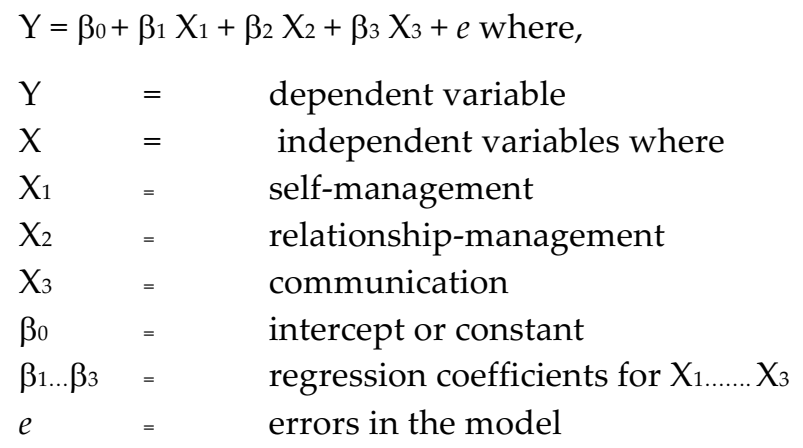

\section{Level of Significance}

In this study, a ninety-five percent confidence level $(\mathrm{p}<0.05)$ was set as the criterion level for determining statistical significance. This level has been fixed based on the arguments provided by established statisticians. For instance, according to Cramer (1997), the level of $p<0.05$ is the conventional probability for decision that the result is not due to chance.

\section{Results and Discussion}

\section{Relationship between Independent Variables and Job Performance}

As depicted in Table 1, emotional intelligence $(\mathrm{r}=.70, \mathrm{p}<0.05)$ was positively related to job performance and it was statistically significant. The magnitude of correlation between emotional intelligence and job performance was .70, which according to Salkind (2006) was a strong relationship. Thus, hypotheses 1 was supported. The strong relationship was found to exist between emotional intelligence and job performance. The positive correlation coefficient of emotional intelligence indicated that as this variable increased, so did job performance.

The zero-order correlations are the simple Pearson's correlation coefficients that showed emotional intelligence had a large positive correlation with job performance. The correlation was significant $(\mathrm{p}<$ 0.05). This seemed to indicate that as level of emotional intelligence increased, the level of job performance will be also increased. This study has empirically demonstrated that job performance increased when the academic administrators were emotionally intelligent.

Table 1 Pearson Correlation Coefficient between Emotional Intelligence and Job Performance

\begin{tabular}{llll}
\multicolumn{2}{l}{ Variables } & $\mathbf{r}$ & $p$ \\
\hline $\mathrm{Y}$ & Job Performance (20) & - & - \\
$\mathrm{X}$ & Emotional Intelligence (16) & $0.70^{* *}$ & 0.000 \\
\hline $\begin{array}{l}\text { Notes: } \\
\text { coefficients, } \mathrm{p}<0.05 .\end{array}$
\end{tabular}




\section{Relationship between Emotional Intelligence Dimensions and Job}

Table 2 Pearson Correlation Coefficient between Emotional Intelligence Dimensions and Job Performance

\begin{tabular}{llll}
\hline \multicolumn{2}{l}{ Variables } & $\mathrm{r}$ & $p$ \\
\hline \hline $\mathrm{Y}$ & Job Performance (20) & - & \\
$\mathrm{X}_{1}$ & Self-management (6) & $0.64^{* *}$ & 0.000 \\
$\mathrm{X}_{2}$ & Relationship-management (6) & $0.62^{* *}$ & 0.000 \\
& & & \\
$\mathrm{X}_{3}$ & Communication (6) & $0.54^{* *}$ & 0.000 \\
& & & $0.70^{* *}$ \\
\hline \hline
\end{tabular}

Notes: Figures in parentheses are the number of items measuring each construct; $n=59$. zero-order coefficients, $\mathrm{p}<0.05$.

As depicted in Table 2, emotional intelligence dimensions: self-management $(r=0.64, p<0.05)$, relationship-management $(\mathrm{r}=0.62, \mathrm{p}<0.05)$ and communication $(\mathrm{r}=0.54, \mathrm{p}<0.05)$ were positively related to job performance. They were all statistically significant. The magnitude of correlations between dimensions of emotional intelligence and job performance was a strong relationship (Salkind, 2006). The strongest relationship was found to exist between self-management and job performance. Therefore, given the data, hypotheses 2, 3 and 4 were accepted.

The results of the study revealed that all the emotional intelligence dimensions were positively related to job performance with the highest correlation of 0.64 for self-management, followed by 0.62 for relationship-management and communication (0.54). Self-management and relationshipmanagement has a strong relationship with job performance which according to Salkind (2006). Meanwhile communication and job performance was fall into a moderate relationship. It seemed to indicated that academic administrators emphasized more on self-management and relationshipmanagement compared to communication among their staff.

The zero-order correlations are the simple Pearson's correlation coefficients that show selfmanagement had the largest positive correlation with job performance, followed by relationshipmanagement, and communication. All the correlations were significant $(p<0.05)$. This means that as level of self-management increased, so did the level of job performance and the same happened to relationship-management communication. And, to test the three hypotheses simultaneously, multiple regression was conducted where job performance was the dependent variable. The three hypotheses 2, 3 and 4 were well supported.

This was consistent with past findings that suggested there was an association between emotional intelligence and human behavior that can influence the employees' positive work attitudes behavior, and performance (Carmeli, 2003). Emotional intelligence plays an important role in determining success at workplace and is a very important element for academic staff. The findings provide evidence that emotional intelligence does exist in the workplace and has a great impact on job performance. 


\section{Predictors of Job Performance}

Table 3 Stepwise multiple regression of job performance

\begin{tabular}{|c|c|c|c|}
\hline Independent Variables & $\mathbf{R}$ & $\mathbf{R}^{2}$ & $p$ \\
\hline Self-management $\left(\mathrm{X}_{1}\right)$ & 0.64 & 0.41 & 0.002 \\
\hline Relationship-management $\left(\mathrm{X}_{2}\right)$ & 0.69 & 0.48 & 0.007 \\
\hline
\end{tabular}

Note: R: Correlation, R2: R-squared.

As depicted in Table 3, the best predictor chosen by the statistic program was self-management, one of the components of emotional intelligence. Self-management produced a multiple regression coefficient $(\mathrm{R})$ of 0.64 . The coefficient of determination $\mathrm{R}^{2}$ of self-management showed that this variable by itself contributed $41 \%$ of the variance in job performance. The second predictor chosen was relationship-management, second components of emotional intelligence. It was chosen on the basis that it improved the prediction achieved by the first factor, self-management, where the combination of self-management and relationship management produced a multiple correlation coefficient of .69. The coefficient of determination $\mathrm{R}^{2}$ of relationship-management showed that this variable by itself contributed $7 \%$ of the variance in job performance.

As depicted in Table 4, the largest beta coefficient was .41 which for self-management. This means that this variable makes the strongest unique contribution to explaining the job performance, when the variance explained by all other predictor variables in the model was controlled. It suggested that one standard deviation increase in self-management was followed by 0.41 standard deviation increase in job performance. The Beta value for relationship-management was the second highest $(0.36)$ indicating that it made the least contribution to job performance compared to self-management.

Table 4 Estimate of coefficients for the model

\begin{tabular}{lccccc}
\hline \hline Dimension & $\begin{array}{c}\text { B } \\
\text { (Unstandardized } \\
\text { Coefficients) }\end{array}$ & Std. Error & $\begin{array}{c}\text { Beta } \\
\text { (Standardized } \\
\text { Coefficients) }\end{array}$ & t & $p$ \\
\hline Constant & 1.12 & 0.43 & & 2.60 & 0.012 \\
Self-management $\left(\mathrm{X}_{1)}\right.$ & 0.42 & 0.13 & 0.41 & 3.27 & 0.002 \\
Relationship-management $\left(\mathrm{X}_{2}\right)$ & 0.31 & 0.11 & 0.36 & 2.83 & 0.007 \\
\hline \hline
\end{tabular}

As depicted in the coefficient table (see table 4), the estimates of the model coefficient for $\beta_{0}$ was $1.12, \beta_{1}$ was 0.41 and $\beta_{3}$ was 0.36 . Therefore, the estimated model was as below:

$\mathrm{Y}=1.12+0.41\left(\mathrm{X}_{1}\right)+0.36\left(\mathrm{X}_{2}\right)+e$

where:

$\begin{array}{lll}\mathrm{Y} & = & \text { job performance } \\ \mathrm{X} & = & \text { emotional intelligence } \\ \mathrm{X}_{1} & = & \text { self-management } \\ \mathrm{X}_{2} & = & \text { relationship-management } \\ e & = & \text { errors in the model }\end{array}$

\section{Conclusions}

Based on these findings, it can be concluded that the level of emotional intelligence among academic administrators in UiTM Southern Zone Campuses was high. As indicated in the preceding chapter, emotions do exist in the workplace and that they have a great impact in the workplace and on the employees. It is believed that emotions and their regulation may be an important factor in explaining many aspects of organizational life and the employees who work within the organization. Emotional intelligence can help academic administrators of UiTM to be more competent at their own 
work as well as in their relationships with others, especially in working more productively with others and influencing others to work more productively with them.

Based on these findings also, it can be concluded that the level of job performance among academic administrators in UiTM Southern Zone Campuses was high. As indicated in the preceding chapter, organizations that were trying to achieve a targeted goal such as UiTM need highly performing individuals in order to meet their goals and to achieve competitive advantage. It was also found that organizations with specific vision and mission were increasingly implementing teamwork and other group work arrangements. However, because teams are composed of individuals, team processes and team performance cannot be completely understood and improved without taking individual performance into account.

Prior research has indicated that individuals who were emotionally intelligent exhibited the most positive outcomes. The present study provides additional support for this proposition. The high levels of emotional intelligence dimensions (self-management, relationship-management and communication) as shown in the findings are consistent with prior research. Goleman (1998a) argued that by itself emotional intelligence probably was not a strong predictor of job performance. Rather, it was the emotional competencies such as self-management, relationship-management and communication that predict job performance.

Besides that, it was also found that the three dimensions of emotional intelligence were significantly and positively correlated with job performance. These findings are in line with Goleman (1998a) who claimed that the abilities associated with emotional intelligence are important for success in many areas in life especially performance in the workplace. Furthermore, Goleman also claimed that there was a considerable body of research which suggested that a person's ability to perceive, identify, and manage emotion provided the basis for the kinds of social and emotional competencies that are important for success in almost any job and thus, this particular set of abilities will become increasingly important in the future.

The results of the regression analyses in the study were also consistent with the previous correlation analyses. Two emotional intelligence dimensions: self-management and relationshipmanagement were found to be among the best dimensions in explaining job performance. The findings of this study also support a positive effect of emotional intelligence on the success of the administrators at work. This is particularly important to the belief that management skills specifically recognize the need to develop and acquire skills for managing people and that emotional intelligence may have a critical role in the creation of effective leadership (Whetton, 2001).

It also found that communication was excluded in regression analysis because it did not contribute in significance variable towards job performance. This finding was also supported by a number of scholars such as Cummings and Schwab (1973) and Schneider, (1977). They have argued that selfratings can promote personal development, improve communication between supervisors and subordinates, and clarify differences of opinion between supervisors and managers.

To conclude, this study investigating into the relationships of the multidimensional aspects of emotional intelligence and job performance provide significant results. Studies of this field have not been heavily established by prior studies especially in a non-western environment like universities in Malaysia. This study reported seemed to demonstrate that western management and western organizational behavioral frameworks, models and theories that have been used in past research were also valid for use in a non-western setting like Malaysia. The study should be extended to include a larger population of academician from other universities in Malaysia so that it would be able to provide stronger evidence on western findings. 


\section{References}

Berenson, M. L., \& Levine, D. M. (1996). Basic Business Statistics: Concepts and Applications. Fifth Edition. Eaglewood Cliffs, NJ: Prentice Hall.

Carmeli, A. (2003). The relationship between emotional intelligence and work attitudes, behavior and outcomes: An examination among senior managers: Journal of Managerial Psychology, 18(8), 788813.

Coolican, H. (1999). Research Methods and Statistics in Psychology. London: Hodder\& Stoughton.

Cooper, R. and Sawaf, A. K. (1997), Executive EQ: Emotional Intelligence in Leadership and Organisations. New York: Grosset Putnum.

Cooper, R. K. (1997). Applying emotional intelligence in the workplace. Training and Development, 51(12), 31-38.

Cramer, D. (1997). Basic statistics for social research. New York: Routledge.

Creswell, J. W. (1994). Research design: Qualitative and quantitative approaches. USA: Sage Publications, Inc.

Cummings, L. L., \& Schwab, D. P. (1973). Performance in organizations: Determinants and Appraisal. Glenview, IL: Scot, Foresman.

Edwards, M., \& Ewen, A. (1996). 360 Feedback: The Powerful New Model for Employee Assessment and Performance Improvement. New York: AMACOM.

Fineman, S. (1997). Emotions and management learning. Management Learning, 28(1), 13-25.

Goleman, D. (1998). What makes a leader? Harvard Business Review, 76, 93-104.

Goleman, D. (1995). Emotional intelligence. New York: Bantam Books.

Goleman, D. (1998a). Working with emotional intelligence. New York: Bantam Books.

Goleman, D. (1998b). What makes a leader? Harvard Business Review, 77, 93-102.

Goleman D. (2001). The Emotional Intelligent at Workplace: How to Select for Measure and Improve Emotional Intelligence in Individuals, Groups and Organizations. San Francisco. C. A., 27-44.

Kotter, J. P. (1990). A Force for Change - How Leadership Differs from Management. New York: The Free Press.

Krejcie, Robert V., \& Morgan, Daryle W. (1970). Determining sample size for research activities. Educational and Psychological Measurement.

Mayer, J. D., \& Salovey, P. (1990). Emotional intelligence. Imagination, Cognition and Personality, 9, 185211.

Meyer, J. P., \& Allen, N. J. (1997). Commitment in the workplace: Theory, Research and Application. Thousand Oaks: Sage Publication.

Nowack, K. (1997). Executive View 360. In Fleenor, J. \& Leslie, J. (Eds.). Feedback to managers: A review and comparison of sixteen multi-rater feedback instruments (3rd edition). Center for Creative Leadership, Greensboro, NC.

Ngah, Rohana, Jusof, K., \& Rahman, Z. A. (2009). Emotional intelligence of Malaysian academia towards work performance. International Journal of Education Studies, 2(2).

Salkind, N. J. (2006). Exploring research. Sixth ed. New Jersey: Pearson Education. Inc.

Salovey, P. \& Mayer, J. D. (1990). Emotional intelligence. Imagination, Cognition and Personality, 9, 185211.

Schneider, C. E. (1977). Operational utility and psychometric characteristics of behavioral expectation scales. A cognitive reinterpretation. Journal of Applied Psychology, 62, 541-548.

Whetton, D. A. (2001). Developing Management Skills. $5^{\text {th }}$ ed. Upper Saddle River, NJ: Prentice-Hall.

Yan-hong, Yao, Run-tian, Wang, \& Yuan-Wang, Karen. (2009). The influence of emotional intelligence on job performance: Moderating effects of leadership style. Journal of International Conference on Management Science \& Engineering, 16, 14-16. 